\title{
Genealogia femenina en Els jeroglífics i la pedra de Rosetta (1976) de Carmelina Sánchez-Cutillas
}

\author{
Female genealogy in Els jeroglífics i la pedra de Rosetta (1976) \\ by Carmelina Sánchez-Cutillas
}

\author{
Verònica Cantó Doménech \\ canto_ver@gva.es \\ Acadèmia Valenciana de la Llengua
}

\begin{abstract}
Resum: L'objectiu d'aquest article és fer una aproximació a la genealogia femenina que transita pel poemari Els jeroglifics $i$ la pedra de Rosetta, amb la finalitat de comprovar que la presència de determinades figures femenines no és casual, sinó que respon a una clara consciència de gènere de Carmelina Sánchez-Cutillas; així com també verificar que la tipologia femenina s'oposa a un seguit de figures masculines, associades a conceptes d'autoritat i opressió, tan representatius de la visió androcèntrica patriarcal de la societat franquista. A partir de l'anàlisi d'aquest poemari, en el qual l'autora incorpora tot el seu extraordinari bagatge cultural i fa una exhibició de la seua erudició, ens aventurem a oferir una nova perspectiva d'anàlisi basada en l'estudi de la simbologia que amaguen les catorze figures femenines mitològiques presents en l'obra, caracteritzades per trets com la universalitat, la fortalesa o la saviesa, que són recuperades per l'escriptora com a veus del passat que retornen al present amb una gran força evocadora, amb afany de denúncia, per a rescatar-nos del silenci, del buit, de la foscor, per a retornar-nos la consciència, la identitat i la dignitat individual i col lectiva.
\end{abstract}

Paraules clau: Carmelina Sánchez-Cutillas, figura femenina, mitologia, simbologia, consciència de gènere

Abstract: The purpose of this article is to approach female genealogy in the poetry collection Els jeroglifics i la pedra de Rosetta, in order to prove that the presence of certain female figures is not accidental, but rather responds to a clear gender awareness on the part of Carmelina Sánchez-Cutillas. The paper also aims to verify that female typology is opposed to a series of male figures, associated with concepts of authority and oppression, representative of the androcentric patriarchal view of the Francoist society. From the analysis of this book of poems, in which the author incorporates all of her extraordinary cultural background and manifests her erudition, we venture to provide inside into the study of the symbology underlying the fourteen mythological female figures present in the work. They are characterized by features such as universality, strength or wisdom, which are recovered by the writer as voices of the past that return to the present with great evocative force and with a desire to denounce, to rescue us from the silence, the emptiness, the darkness, to regain our consciousness, identity and individual and collective dignity.

Keywords: Carmelina Sánchez-Cutillas, female figure, mythology, symbolism, gender awareness

DATA PRESENTACIÓ: 01/05/2021 ACCEPTACIÓ: 14/05/2021 •PUBLICACIÓ: 01/06/2021

SCRIPTA, Revista internacional de literatura i cultura medieval i moderna, núm. 17 / juny 2021 / pp. 485 - 505 
Ara faig estranys poemes, ho sé, si són poemes, encara. Tinc dins de mi un món misteriós, on bateguen les flors i els minerals, les aus

i la mitologia, els homes i l'astronomia, i la mar i el vent. Encara no sé si són poemes (Carmelina Sánchez-Cutillas, Diari, 1964).

\section{Introducció}

Iniciem el present article amb la veu i els pensaments de Carmelina Sánchez-Cutillas extrets del diari personal de l'escriptora datat en 1964. Sense cap mena de dubte, aquestes línies són una clara referència al poemari que veuria la llum més d'una dècada després sota el títol Elsjeroglifics i la pedra de Rosetta, qualificat per Lluís Alpera (1997: 17) com «el millor poemari de Carmelina Sánchez Cutillas i un dels més originals i interessants de tota la recerca formal i estètica produïda en el camp de la poesia al País Valencià als anys setanta. I segurament, d'haver estat estudiat i analitzat degudament, fóra un dels poemaris més innovadors produïts dins la literatura catalana dels darrers vint anys».

La lectura del paràgraf del diari personal de l'escriptora ens convida a preguntar-nos sobre les raons que podrien motivar la poetessa a emprar, d'una banda, el qualificatiu estranys i, de l'altra, a expressar els seus dubtes sobre si el que està escrivint són poemes. Malauradament es tracta d'una pregunta retòrica, però com a mínim ens serveix per a constatar que l'autora es troba en un moment de plena efervescència creativa literària amb poemes que van des del realisme social fins a versos que representen l'expressió del formalisme simbòlic. Així mateix ens permet l'atreviment de conjecturar que el caràcter críptic, laberíntic i hermètic que la majoria de la crítica ha destacat del poemari Els jeroglifics i la pedra de Rosetta, ja es trobava en l'embrió de l'escriptura.

Dit això, la intenció d'aquest article és fer una aproximació a la genealogia femenina que sura pels versos d'Els jeroglifics i la pedra de Rosetta, amb la finalitat, d'una banda, de comprovar que la presència de determinades figures femenines en el poemari no és casual, sinó que respon a una intencionalitat concreta per part de Carmelina Sánchez-Cutillas, ja que al nostre parer obeeix no sols a motius identitaris, sinó també a la consciència de pertinença de l'autora a un determinat col lectiu, el de les dones, és a dir, respon a una clara consciència de gènere de l'escriptora. I, de l'altra, també té la intenció de verificar que eixes figures femenines generalment s'oposen a un seguit de figures masculines que, per regla general, apareixen associades a l'autoritat, l'opressió i la repressió. Al capdavall són símbols representatius de l'androcentrisme patriarcal tan imperant en la societat del moment històric en què viu Sánchez-Cutillas, és a dir, la postguerra i la dictadura franquista. ${ }^{1}$ Com bé ha destacat M. Àngels Francés (2015: 15) «són les figures mítiques femenines, les que, amb una

1 A fi de disposar de més informació sobre la situació històrica, social i cultural en què es trobaven les escriptores valencianes de la postguerra, que es van rebel lar contra el paper atorgat a la dona pel règim franquista, vegeu especialment Lacueva (2020). 
Verònica Cantó Doménech. Genealogia femenina en Els jeroglifics i la pedra de Rosetta (1976) de Carmelina Sánchez-Cutillas

doble veu, aquella que prega però també parodia, subverteixen les lleis establertes, atempten contra els centres de poder patriarcal, trenquen la closca compacta de silenci que ha pesat sobre elles a través dels segles».

\section{Valoració del poemari per part de la crítica}

Abans, però, d'iniciar el tractament de la genealogia femenina en Els jeroglífics i la pedra de Rosetta, considerem oportú saber quina ha sigut l'anàlisi i la valoració que la crítica ha aportat sobre aquest poemari, una obra de la qual la mateixa Sánchez-Cutillas diu «si he fet alguna cosa bona i intel ligent, és aquest llibre» (Ventura Melià 1979: 39). Observem, contràriament al que l'autora podria desitjar, que el poemari no ha estat ni de bon tros suficientment analitzat, segurament per la complexitat intrínseca de la pròpia obra, extremadament inintel ligible si no es disposa del coneixement enciclopèdic de què gaudia l'escriptora. ${ }^{2}$ Sánchez-Cutillas era conscient de la dificultat d'aquests poemes quan en una de les poques entrevistes concedides al llarg de la seua vida declarava: «Ara bé, possiblement és un llibre per a minories» $\mathrm{i}$ afegia amb un punt àcid d'ironia càustica deixant en suspens el veritable pensament: «Clar que també pense que si el pitecantropus erectus, o dit més suaument, l'homo sapiens llig allò que l'editor o els crítics volen...» (Ventura Melià 1979: 39). Per això, si exceptuem els treballs d'Alpera (1997 i 2010) i, especialment, el monogràfic de Francés (2015), que fan un esforç encomiable per desxifrar el significat del poemari i ens ofereixen algunes possibles interpretacions que donen determinades claus i pautes concretes per a la lectura i la relectura dels versos, la resta dels investigadors que s'hi han enfrontat ens ofereixen descripcions bastant generals, a manera de pinzellades impressionistes, conscients de la dificultat de desentranyar la complexa arquitectura poemàtica a causa de la seua càrrega simbòlica i críptica. Cal, a parer nostre, començar a estirar el fil del cabdell i parar-se en cada detall dels «jeroglífics» que planteja el poemari.

La nostra intenció a l'hora d'enumerar cronològicament i citar literalment les paraules que han fet servir els pocs crítics que s'han enfrontat a l'anàlisi del poemari és fer un estat de la qüestió de la recerca feta fins al moment, i evidenciar com la dificultat de comprensió i d'interpretació dels versos carmelinians deuen haver sigut un dels entrebancs per a fer una crítica més aprofundida del significat i del simbolisme que s'amaguen darrer dels vint-i-huit jeroglífics. D'altra banda, observem de les seues paraules que tots ells intenten situar aquesta obra en el context de la poesia produïda als anys 70 en el conjunt de la literatura catalana.

2 Constatem el coneixement enciclopèdic de Sánchez-Cutillas a través de la seua biblioteca eclèctica de més de 2.000 volums en què destaquen obres de temàtica històrica, literària, del cicle artúric i de cultures diverses de base mediterrània. Aquesta biblioteca es conserva en els fons de la Biblioteca Valenciana Nicolau Primitiu. (vegeu l'inventari en l'arxiu http://bv.gva.es/documents/167016322/167348540/S\%C3\%A1nchez+-+Cutillas+Mart \%C3\%ADnez $\% 2 \mathrm{C} \% 20$ Carmelina/869c0c60-cd4a-4826-810c-8cb44d67e5f2). D’altra banda, Del Romero Sánchez-Cutillas (2020) evoca el sancta sanctorum de Carmelina Sánchez-Cutillas que conformava el seu despatx i la seua estimada i valuosa biblioteca.

SCRIPTA, Revista internacional de literatura i cultura medieval i moderna, núm. 17 / juny 2021 / pp. 485 - 505 ISSN: 2340-4841 ·doi:10.7203/SCRIPTA.17.20920 
Verònica Cantó Doménech. Genealogia femenina en Els jeroglífics i la pedra de Rosetta (1976) de Carmelina Sánchez-Cutillas

Ens aquest sentit, uns dels primers a parlar del poemari són Ferran Carbó i Vicent Simbor (1993: 99) els quals afirmen que Els jeroglifics i la pedra de Rosetta

\begin{abstract}
representa un cas singular dins el panorama literari valencià d'aleshores. D'una banda, per la incorporació de la prosa poètica [...] amb un llenguatge analògic, elusiu, indirecte, mític i, sobretot, simbòlic [...]. De l'altra, perquè es configura com una mena de conjunt coherent amb referències mitològiques, religioses i històriques. [...] És un llibre que sintonitza plenament amb el formalisme de la poesia dels anys setanta.
\end{abstract}

Per la seua part, Jaume Pérez Montaner (1993: 100-101) diu que es tracta d'un

\begin{abstract}
poemari dens i complex que associa i relaciona les més diverses tradicions culturals, religioses i mitològiques, des de l'antic Egipte o la pròpia tradició medieval del món occidental fins a l'Extrem Orient o a les llegendes pre-colombines, en el lirisme d'unes proses que ens deixen a les portes d'un món que intuïm ple de subtileses i misteris. [...] Els poemes d'Els jeroglifics i la pedra de Rosetta, són una de les excepcions evidents en el conjunt de la seua obra i en el panorama de la moderna poesia catalana al País Valencià.
\end{abstract}

D'altra banda Enric Balaguer (1993: 22) considera que l'autora «s'endinsa en uns mons mitològics antics (grec, egipci, hindú...) tot cercant una mena de recreació dels orígens del temps i de la cultura».

Així mateix Lluís Alpera (2010: 19), un dels estudiosos que més atenció ha focalitzat en l'obra de Sánchez-Cutillas i que més ha reivindicat la figura literària de l'escriptora, amb qui tenia lligams d'amistat, lamenta que Carmelina Sánchez-Cutillas mantenira un llarg autoexili de vora 30 anys per la decepció de l'autora davant del silenci de la crítica respecte als seus dos últims poemaris, més interessada per Matèria de Bretanya. Alpera opina que «potser una altra escriptora s'hauria conformat fruint del prestigi per una sola obra. Però Carmelina havia fet un gran esforç d'erudició i d'estètica dins la lírica i necessitava un altre reconeixement a primers dels 80 que mai no va tenir». Concretament pel que fa a l'obra que ens ocupa, Lluís Alpera (2010: 23-24) considera que

\footnotetext{
una cultura tan extraordinàriament àmplia i diversa, acompanyada d'un lèxic sorprenentment divers i insòlit a nivell poètic, havia de ser fruit d'una sedimentació harmònica al llarg d'una vida d'observació i d'estudi continu. [...] L'aprenentatge terminològic de la natura i de les ciències experimentals venia de la mà del seu avi, l'alteà Francesc Martínez i Martínez [...]. Després vindrien les llargues hores de lectura i d'escodrinyament a través de la història medieval i les antigues civilitzacions.
}

A més, Alpera (2010: 24-26) va més enllà en un intent d'oferir-nos possibles lectures del poemari i, concretament, n'apunta tres:

una primera, altament simbòlica, plena de referències mitològiques $\mathrm{i}$ culturals [...]; una segona, amb referents que, en clau també simbòlica, podrien apuntar a contextos històrics, principalment a les acaballes del franquisme [...]; i, finalment, una tercera més agosarada quan 


\begin{abstract}
es pregunta si tot aquest desplegament de simbologia cultural i ampli joc metafòric de l'autora, ¿no seria un tramat d'emmascarament de la mateixa vida de la poeta en un moment donat? ¿No seria tota una autèntica eclosió catàrtica de la seua pròpia vida interior i d'alguna que altra conjuntura personal, decisiva en la seua trajectòria? [...] Podríem suggerir que Els jeroglifics i la pedra de Rosetta, al costat de l'optimisme i el coratge assenyalats, mostren alhora, a un nivell d'estructura profunda, una frustració sexual, una desil lusió per la vida viscuda, un penediment d'alguns actes i una lluita envers la condició de dona.
\end{abstract}

Finalment, M. Àngels Francés (2015: 9-10) afirma que en aquesta obra l'autora

\begin{abstract}
desafia el silenci ancestral, jeroglífic, imposat per l'hostilitat de l'entorn. En el poemari [...] s'hi reflecteix el món com una massa de llenguatges en efervescència, cadascun amb els seus propis distintius formals, que competeixen per manifestar-s'hi individualment. Així, un extraordinari bagatge de referències mitològiques, religioses, científiques i històriques [...] construeixen el laberint inhòspit del poemari, en un intent per fer alquímia dels fonaments de la tradició cultural i transformar-los en l'expressió de la rebel lia, de la ira que subjau, com en un palimpsest, sota els escrits, [...] on s'usa el llenguatge com a caixa de ressonància de cultures històriques o mítiques i les enllaça amb el present per a fer-ne denúncia [...] i on els fils temàtics s'entrellacen els uns amb els altres i conformen així una teranyina compacta, densa.
\end{abstract}

Constatem, doncs, que encara ara, quaranta-cinc anys després de la seua publicació, transitar, abastar la prosa poètica ambigua, hermètica i laberíntica d'Els jeroglifics $i$ la pedra de Rosetta esdevé una tasca àrdua, ingent, fins i tot frustrant, perquè no disposem de la clau que obri tots els panys, malgrat la invitació de l'autora a «desxifrar el vell jeroglífic» a fi d'esbrinar «què hi haurà al límit de l'amor, si la dalla i el llamp són els trofeus de l'Emissari; perquè la carn i el blat encara bateguen, i la torxa i la flama, tribut dels homes a la nit, obren rierols de sang sobre els blocs de ceràunia» (Poema 1) ${ }^{3}$. No obstant això i considerant l'escassesa de treballs sobre el poemari, ens aventurem, potser de manera agosarada, a oferir una nova perspectiva d'anàlisi amb la finalitat d'intentar descobrir, d'una banda, la simbologia que amaguen cadascuna de les catorze figures femenines presents en els vint-i-huit poemes i, de l'altra, a desvetllar la rellevància que Carmelina Sánchez-Cutillas atorga a la dona en el poemari com a protagonista i no com a simple espectadora de la història, que ens ajude a abastar el posicionament de l'escriptora respecte a la seua inequívoca consciència de gènere, molt present en tota la seua producció literària i investigadora.

\title{
3. Genealogia femenina en Els jeroglífics i la pedra de Rosetta
}

Després de la introducció i la revisió feta en els apartats anteriors, ens endinsarem ara en el tema objecte d'aquest article, això és, l'estudi de la genealogia femenina present en el poemari. Abans, però, ens referirem al concepte pròpiament dit, això és, al que s'entén per genealogia femenina i

3 A partir d'ací citarem com a referència els números dels poemes extrets de l'obra Carmelina Sánchez-Cutillas (1997): Obra poètica, València, Generalitat Valenciana, Consell Valencià de Cultura, pp. 157-191.

SCRIPTA, Revista internacional de literatura i cultura medieval i moderna, núm. 17 / juny 2021 / pp. 485 - 505 ISSN: $2340-4841 \cdot$ doi:10.7203/SCRIPTA.17.20920 
a la raó per la qual és pertinent estudiar-la en el poemari, ja que no es tracta solament de fer una descripció dels personatges femenins presents en els poemes, sinó també d'establir quins lligams de reconeixement i de transmissió de la saviesa femenina hi actuen, ja que Sánchez-Cutillas no solament recupera les figures femenines del passat, sinó que els ret homenatge i les invoca com a fonts d'autoritat, amb la finalitat d'obtenir respostes i de dotar el jo líric de la potestat de qüestionar el discurs imperant a través de veus de dones, la saviesa de les quals és inqüestionable, perquè han esdevingut mites en el sentit que provenen de les cultures ancestrals que conformen la base de la nostra civilització. ${ }^{4}$

Entenem la genealogia com la ciència que estableix el parentiu entre persones i llinatges i n'estudia l'origen, la descendència i les aliances. Les genealogies es teixeixen estirant i creuant els fils de la Història que es disposen en un ordim per a configurar, en un teler imaginari, un arbre genealògic que ens diu qui som i d'on venim.

Dit això, és més que evident que la història gran, i potser també la petita, ha estat escrita amb veu masculina, $i$ fins que els moviments feministes van rescatar les dones de l'oblit per a afermar i arrelar la seua identitat i atorgar valor i rellevància al concepte de gènere, l'aportació intel lectual femenina va ser intencionadament ignorada, ocultada, silenciada i invisibilitzada pel sistema patriarcal que sempre ha intentat excloure les dones dels camps del saber, sense reconéixer els coneixements que posseïen, dels quals eren dipositàries des de ben antic especialment a través d'una cultura oral transmesa de generació en generació, i mantenint-les en una situació de desigualtat permanent.

Per això, el fet de dotar de sentit els sabers femenins i l'ampli ventall de coneixements de les dones a partir de les seues experiències vitals, del seu bagatge en diferents disciplines, significa donar-los entitat i situar-los en un món i en una cultura compartida i comuna, perquè aquesta saviesa no ha eixit del no-res, té uns precedents, respon a un llegat que ens ha estat transferit al llarg del temps i tindrà, sens dubte, una continuïtat en l'esdevenidor, perquè l'herència i la individualitat són compatibles i complementàries. Fer genealogia femenina és l'única manera de confegir la construcció d'una identitat de gènere, és potenciar les pròpies figures femenines, ser conscient del nostre llegat i crear

\footnotetext{
4 En aquest sentit seria molt interessant i engrescador fer un estudi de la tipologia femenina que apareix en tota la producció literària i d'investigació de Carmelina Sánchez-Cutillas, prenent en consideració obres fonamentals, que tracten de definir una tradició específicament femenina en la literatura, com ara Literary Women (1976) d'Ellen Moers, que ofereix una visió completa sobre l'abast, la varietat i el desenvolupament de la tradició literària conformada per escriptores angleses, franceses i americanes des de principis del segle XVIII i examina com el fet de ser dones va influir tant en la seua vida com en la seua escriptura; A Literature of Their Own (1977) d'Elaine Showalter, que situa les obres d'escriptores britàniques famoses al costat de les menors o oblidades, construint una continuitat d'influència $i$ inspiració, així com una imatge més completa de les condicions socials en què s'han produït els llibres sobre dones; i The Madwoman in the Attic (1979) de Sandra Gilbert i Susan Gubar, que examinen la literatura victoriana des d'una perspectiva feminista i insten les escriptores a lluitar per una autodefinició autònoma més enllà de la dicotomia de l'«àngel» o el «monstre», una dicotomia que ve imposada per la visió patriarcal reduccionista dels rols de les dones. Entenem, però, que aquesta proposta supera els límits del present article i ha de ser objecte d'un estudi monogràfic més aprofundit, que ja tenim iniciat i deixem per a més avant.
}

SCRIPTA, Revista internacional de literatura i cultura medieval i moderna, núm. 17 / juny 2021 / pp. 485 - 505 ISSN: 2340-4841 ·doi:10.7203/SCRIPTA.17.20920 
una tradició perdurable. D’altra banda, el concepte de genealogia també implica reconéixer tots els fils que han teixit la història de les dones, des dels més forts, aquells que ens han arribat des del passat al present i que han resistit el pas del temps, fins als fils més febles representats per la preservació de la quotidianitat femenina. Tots ells formen el mosaic d'una història, la de les dones, que ha sigut injustament silenciada.

I és precisament amb un acte conscient de recuperació, reconeixement i reivindicació de les dones mítiques del passat que Carmelina Sánchez-Cutillas contribueix a fer genealogia femenina en el poemari que ens ocupa i en tota la seua obra literària. Igualment rescata la memòria de les dones en la seua tasca com a investigadora en recuperar-nos semblances de reines, santes i escriptores de la Corona d'Aragó, amb apel lacions constants a la sororitat. Així en la conferència impartida en el marc del I Encontre Internacional de Dones de la Mediterrània, celebrat a València entre el 24 i el 28 de novembre de 1992, es declarava
enemiga acèrrima d'eixa manifestació de dret de possessió i de poder de l'home, del mascle, sobre la dona, un exercici secular i sistemàtic d'allò que avui en dia es denomina masclisme. Des de sempre, la dona ha estat subordinada a la voluntat, al caprici, als desitjos i, fins i tot, a la crueltat de l'home

i es preguntava «quantes Ifigènies, desconegudes i silenciades, han passat i passen per la història?». Així mateix Sánchez-Cutillas fa genealogia en l'article publicat el 6 de juny de 1962 sota el títol «La dona a la València medieval. Mite i realitat» on l'escriptora després de fer una descripció de la vida femenina valenciana a través de la mirada de figures literàries com Francesc Eiximenis, Joanot Martorell, Ausiàs March, Isabel de Villena o Arnau de Vilanova, acaba concloent amb les paraules següents:
abans de finir podríem nomenar un nombrós estol de dones que varen ésser famoses a la nostra història i a la nostra literatura: unes per la seua santedat, altres per la seua coqueteria, $\mathrm{i}$ totes com deia l'Ausiàs March “...havent en si tan gran coneixement, que res no'l fall que tota no's conega...".

I fins i tot també ens parla de nissaga femenina en un manuscrit de 1992 titulat «Dona i literatura» quan afirma:

\footnotetext{
crec que hauria d'aplegar al segle XIX, per a contemplar un retrat de dona fet per una dona -unes heroïnes que, com les germanes Brönte, comencen a rebel lar-se, i a mostrar la seua autèntica condició [...] Al cap i a la fi, som un ésser que ha dormitat al llarg dels segles, i que ara comença a despertar-nos.
}

Comptat i debatut, en vista del que hem assenyalat en els paràgrafs anteriors, és innegable que podem considerar Carmelina Sánchez-Cutillas una precursora de la vindicació del paper de les 
dones al llarg dels segles en la transmissió del coneixement, reconeixent i valorant el llegat transmés des d'una perspectiva de gènere emmarcada dins d'una tradició pròpia.

En aquest sentit observem que al llarg d'Els jeroglifics $i$ la pedra de Rosetta desfilen un seguit de figures femenines que, a més de pertànyer a un passat mític i ancestral, provenen de diverses cultures. Són dones amb una veu potent, evocadora, que ens ofereixen mirades i perspectives diferents, generalment oposades a les veus masculines, els discursos de les quals contradiuen molt sovint. Són dones unides per cultures mil lenàries, que formen part de la mitologia clàssica, del bagatge històric, cultural i referencial de la humanitat, pertanyents majoritàriament a l'antiga cultura mediterrània. Davant dels nostres ulls irrompen amb força figures femenines de la tradició grecollatina (amazones, la Sibil la, sirenes, vestals, cariàtides, Eurídice i Ariadna); de la mitologia egípcia (Isis); de la mitologia fenícia i púnica (Tanit); de la civilització occidental (Ginebra, donzella, princesa); de la tradició cristiana (Emperadriu verge, Abadessa). Són veus femenines universals que Carmelina Sánchez-Cutillas ha volgut recuperar a través dels seus versos, dotant-les d'autoritat, de misteri, de poder, oferint uns altres punts de vista innovadors, enfrontant-les a l'autoritarisme representat per les figures masculines, amb la intenció de reinterpretar els mites, de contradir les normes establertes.

El tema de la denúncia de l'autoritarisme, la repressió, la intolerància, l'opressió, el totalitarisme, el dogmatisme o la injustícia, així com la construcció d'una identitat de gènere mitjançant veus femenines autoritzades que provenen del passat, és una constant en la producció literària i investigadora de Carmelina Sánchez-Cutillas, a través de la qual l'escriptora adopta «una triple rebel lió: contra la submissió lingüística, contra el totalitarisme ideològic i contra totes les intricades i fossilitzades formes de la discriminació per raó de gènere» (Borja Sanz \& Francés Díez 2020: 5). Fins i tot, la mateixa escriptora en la Semblança autobiogräfica que es conserva en el seu llegat a la Biblioteca Valenciana Nicolau Primitiu, es presenta afirmant que «sempre estic del costat del vençuts», en una declaració clara del seu posicionament ideològic.

En aquest sentit, la investigadora Anna Cacciola (2019: 283), en l'estudi on analitza la vinculació entre el règim franquista i la repressió de la identitat lingüística i cultural en les nostres lletres, així com el paper reservat a les dones escriptores, a través dels poemaris Un món rebel (1964) i Conjugació en primera persona (1969), assenyala que

\footnotetext{
la obra poética de Carmelina Sánchez-Cutillas emana de ese sentido de marginación y denuncia cruda y directamente la condición de la mujer, por un lado, y por otro, la injusticia de un mundo en el que reina la falta de libertad e igualdad. Por su interés social y civil, por la reflexión acerca de la cuestión femenina y por su vinculación temática y expresiva con el mejor realismo histórico de la época, puede considerarse la más representativa de las poetas de la primera generación valenciana de la posguerra.
} 
Verònica Cantó Doménech. Genealogia femenina en Els jeroglifics i la pedra de Rosetta (1976) de Carmelina Sánchez-Cutillas

Sánchez-Cutillas se'ns presenta com una dona rebel i compromesa amb les demandes d'un feminisme que despertava a finals de la dècada dels 60 i que continuaria en la dels setanta en consonància amb els anhels de llibertat i renovació d'una societat immersa en un procés de canvi, i col labora amb aquest desvetllament social i cultural recuperant la memòria de les dones, amb una poètica de rebel lia contra la ideologia patriarcal i de reivindicació de la identitat pròpia.

Una prova de la seua consciència de classe i del seu allunyament de les lleis imposades pel franquisme es pot observar en el poema titulat Formem una minoria que pertany al poemari Un món rebel (1964) quan diu:

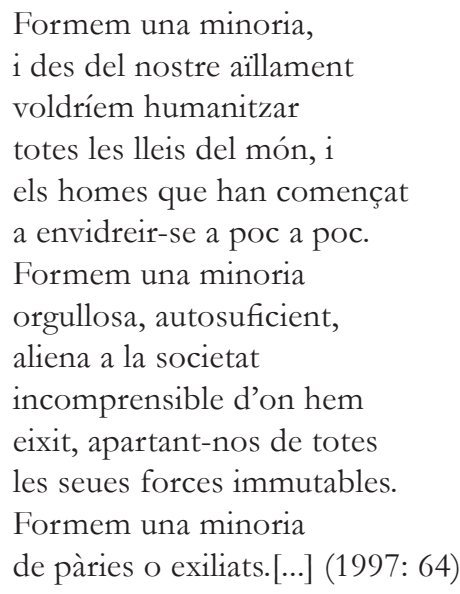

Així mateix, un altra mostra de la seua condició de dona intel lectual marginada que troba en la poesia una via de denúncia, la podem constatar en el poema titulat Per tanta cosa morta! del poemari Conjugació en primera persona (1969):

Tinc por d'escriure, però...

No puc deixar d'escriure

Per tanta cosa morta:

Pel mite de la dona;

Pel treball de la dona;

Pel dolor de la dona;

Per tanta cosa morta...

Hem pastat la farina,

presenciant en silenci

com queien alguns homes.

$\mathrm{O}$ tallàvem la rosa

que més tard posaríem

com emblema del tàlem.

I fèrtils, com la terra,

hem repetit la saba

sense un crit de protesta, 


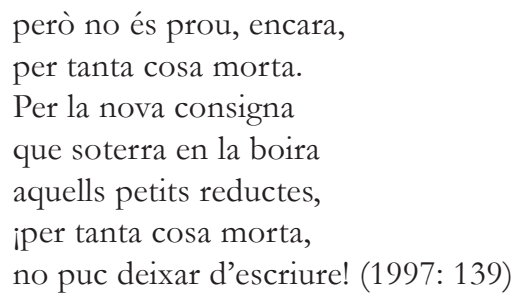

La lluita contra la discriminació per raó de gènere també s'observa en Elsjeroglifics i la pedra de Rosetta, on es percep, com bé assenyala M. Àngels Francés (2015: 13-14)

\begin{abstract}
l'oposició entre figures femenines de ressonàncies mítiques ancestrals i figures masculines igualment evocadores de temps passats, les quals solen anar associades al principi d'autoritat i repressió. [...] la multiplicitat de perspectives femenines que reinterpreten els discursos dels que ostenten el poder, presentats com a monològics i inqüestionables. [...] A les identitats femenines mítiques i ancestrals [...] s'oposa una masculinitat autoritària, fosca, estranya a la veu del poemari.
\end{abstract}

Arribats a aquest punt encetem, doncs, el tractament de la genealogia femenina en Els jeroglifics $i$ la pedra de Rosetta, que esperem que contribuïsca, com hem avançat adés, a esclarir una part dels misteris que s'amaguen darrere dels versos laberíntics.

\title{
3.1 Les amazones
}

Comencem l'anàlisi per les Amazones (Poema 1), que foren considerades en la mitologia grega una antiga nació llegendària de guerreres. Ara bé, l'origen de la història de les amazones ha sigut objecte d'especulació entre investigadors clàssics, i així mentre alguns consideren que les amazones eren un poble purament mític, d'altres entenen que tenen un fonament històric. D’altra banda, també es conjectura que les amazones eren originàriament les sacerdotesses i serventes del temple de Diana. I, fins i tot, una altra teoria es basa en històries de tribus matriarcals, governades per dones que tenien obligacions que en la resta de llocs es consideraven exclusives de l'home, que posseïen els drets de la noblesa i l'herència i que tenien el control suprem de tots els assumptes. D’ací és precisament d'on va sorgir la creença en les amazones com una nació de dones guerreres, organitzada i governada totalment per dones.

Els grecs relacionaven el nom de les amazones amb a-mazōon que significa «sense pit», una etimologia que feia suposar els grecs que les amazones s'anomenaven així perquè s'amputaven un pit per a poder millorar la seua destresa a l'hora de fer servir l'arc, que sembla ser el seu característic instrument de lluita. Un altre origen etimològic ens arriba del sànscrit, on la paraula amazona té el significat de «guerrera». Modernament es va fer servir la paraula amažona per a referir-se a dones fortes $\mathrm{i}$ independents, en contrast amb els estereotips convencionals de dones febles i passives. 
En el cas del poemari, Sánchez-Cutillas ens mostra una amazona purificada en la seua carn i en els seus llavis per «la flor vermella que esclata amb la lluna», és a dir, d'una banda, una dona alliberada de la impuresa fisiològica que s'atribuïa a la menstruació femenina, que a més estava vinculada al cicle lunar $i$, de l'altra, una dona forta que no renunciarà a la paraula ni acatarà cap posició submisa respecte de l'home, que en el poema és representat per la figura del Tetrarca ostentant l'autoritat, però que roman en una «cambra ombrívola», voltat dels seus atributs: cicuta i marbre verd. En definitiva, una imatge poètica colpidora que ens oposa la llum representada per la dona front a l'obscuritat que simbolitza l'home.

\subsection{La Sibil 1a}

Una altra de les figures mítiques i ancestrals és la Sibil la (Poema 4). Segons la tradició grecollatina, és un terme genèric que es fa servir per a denominar les sacerdotesses encarregades de transmetre els oracles, sota la inspiració divina d'Apol lo, el déu de l'endevinació. Eren considerades dones sàvies amb poders sagrats, ja que se'ls havia concedit el do de la profecia, per això exercien de pitonisses i els seus llibres profètics, agrupats en les col leccions d'oracles sibil lins, eren consultats mitjançant uns ritus de gran complexitat, amb la finalitat de conéixer l'esdevenidor. D’altra banda, la Sibil la també simbolitza l'ésser humà en un estat d'èxtasi i elevació tan alt que té la capacitat per a comunicar-se amb la divinitat, per això també són considerades uns instruments de revelació i en l'antiguitat clàssica gaudiren de gran predicament social i polític. En la tradició cristiana, les Sibil les anuncien l'arribada de Crist i així per exemple, per a sant Agustí, desenvolupen un paper semblant al dels profetes bíblics.

Com destaca M. Àngels Francés (2015: 13),

en el poema 4, la novícia "flagel la la nit amb les seues mans d'ocell blau", mentre s'afona el claustre al voltant, i la Sibil la, mítica endevina, prediu un nou futur després de la destrucció total, quan s'hagen sadollat els desigs de venjança i mort, quan la violència dels homes li cedisca a ella el ceptre i carboncle del destí, un nou poder.

En els versos carmelinians, la Sibil la no sols té el poder de l'oracle, de predir el destí, sinó també és dipositària de la capacitat d'enviar mort i destrucció en deixar «volar el corb negre» i llançar «el plom roent». No hem d'oblidar que el corb en la mitologia grega era considerada un au profètica, però també era un emblema de la mort i dels mals averanys.

Així mateix convé posar en relleu que un dels centres religiosos més importants de l'antiga Grècia on se celebraven les sessions oraculars de les sibil les era Delfos, lloc on havia un santuari consagrat a Gea, la deessa de la Terra, que estava custodiat per una serp anomenada Pitó, a qui després d'un combat intens va matar Apol lo amb la finalitat d'instaurar un oracle sota la tutela d'una profetessa o sibil la que, en honor al rèptil mort, també seria coneguda com a pitonissa. No és gens estrany 
Verònica Cantó Doménech. Genealogia femenina en Els jeroglífics i la pedra de Rosetta (1976) de Carmelina Sánchez-Cutillas

que en els orígens de Delfos figure una serp perquè es tracta d'un animal que, segons la tradició, està vinculat als sabers ocults de la Terra amb la qual està en contacte continu a través dels seus moviments. De fet, una possible etimologia de la paraula sibil tla al ludeix a l'arrel sibh- («xiular»), com a onomatopeia del so que fa la serp en arrossegar-se per la terra.

Cal dir, però, que Carmelina Sánchez-Cutillas posa l'accent en la preeminència de Delfos on vol romandre després de fugir del gineceu, això és, de la zona de la casa destinada a les dones, a fi de mamprendre un camí d'alliberament personal, que també podem entendre des del punt de vista formal, estètic i poètic. És un viatge sense retorn, ja que el jo líric no té la voluntat de tornar al present, perquè en eixe cas serà expulsat del gran Temple d'Apol lo, déu que representa l'harmonia, l'ordre i la raó:

\footnotetext{
He fugit del gineceu i vull sobrevolar la llegendària Delfos, com l'au sagrada de les illes calcàries. Però, si retorne al present des del llim de la Història, si intente l'al leació impossible del metall amb la carn flàccida de la meretriu, seré rebutjat del gran Temple d'Apol lo (1997: 159).
}

\subsection{Les sirenes}

En els Poemes 6 i 15 apareixen les figures de les Sirenes, les quals, d'acord amb la mitologia grega, eren nimfes marines, meitat dones, meitat aus. No serà fins a l'Edat Mitjana quan aquests éssers mitològics es representaran amb tors de dona i cua de peix. El textos antics descriuen les sirenes com unes dones d'una bellesa extraordinària $\mathrm{i}$ amb una veu prodigiosa i captivadora, els cants melodiosos de les quals feien naufragar els mariners. En l'Edat Mitjana, el fet de representar les sirenes amb escates, obeïa al fet que se les associava al pecat de la luxúria, raó per la qual apareixen juntament amb les serps, simbolitzant la temptadora Eva. Hui en dia, fem servir l'expressió cant de sirenes per a advertir del perill de deixar-se seduir per falses promeses o paraules aduladores.

Durant el període hel lenístic, les sirenes van passar a ser considerades divinitats del més enllà, el cant de les quals simbolitzava les harmonies celestials i així són representades amb freqüència als sarcòfags. La primera menció de les sirenes apareix en el cant XII de l'Odissea d'Homer, quan Ulisses, de retorn a Ítaca i aconsellat per la maga Circe, va poder evitar el perill i no sucumbir a la seua veu embadalidora tapant les orelles dels seus companys amb cera, mentre que ell, que volia escoltar el seu encisador cant, va ordenar als seus homes que el lligaren al pal major del vaixell.

Si ens centrem en l'anàlisi concret del nostre poemari, observem que en el Poema 6 , el jo líric vol posar «un cíngol d'argelagues al gran cercle de la mar, i de la seua grisa fondària -on dormen les anemones desfullades $\mathrm{i}$ totes les algues», a fi d'impedir «la gran crida de les Sirenes», cosa que tindrà com a conseqüència que «Ulisses, l'heroi anterior a la poesia homèrica» no puga «retornar a l'Arcàdia». En aquest cas, la poetessa pretén dir-nos que si les dones, representades per les Sirenes, emmudeixen, provocaran que els homes, simbolitzats per Ulisses, no puguen retornar a casa, a la seguretat que representa la llar familiar, l'espai íntim de pau i descans. 
Verònica Cantó Doménech. Genealogia femenina en Els jeroglífics i la pedra de Rosetta (1976) de Carmelina Sánchez-Cutillas

\subsection{La donzella}

Per la seua part, la Donzella és una figura femenina que apareix al Poema 2, de qui la poetessa ens diu que «coneix els misteris dels signes i té els ulls d'ametista» per un bes «inèdit» de la qual «gents de la muntanya [...] baraten l'agror del formatge». És, per tant, una dona sàvia, malgrat la joventut que se li pressuposa i, així mateix, és una dona de gran bellesa per posseir uns ulls d'un color extraordinari, gens habitual. D'altra banda, parem atenció en el qualificatiu que la poetessa atorga al bes de la donzella: és un bes inèdit, adjectiu que demostra la puresa d'aquest personatge femení.

La donzella, a més de ser una figura recurrent en la literatura de totes les cultures, forma part d'allò que el poeta i escriptor britànic del segle xix Robert Graves va definir com la Triple Deessa, en un clar paral lelisme amb el concepte cristià de la Santíssima Trinitat, que simbolitza cada una de les etapes de la dona, les quals es relacionen amb les fases lunars, $i$ així la donzella, representada per la lluna creixent, simbolitza la joventut, la inspiració, la creació i l'entusiasme. D’una altra banda tenim la Mare (la lluna plena) i l'Anciana (lluna minvant).

Com hem dit, la donzella va associada a la idea de la virginitat i de la puresa i es tracta d'un personatge que podem relacionar en el poemari de Carmelina Sánchez Cutillas amb altres figures femenines com les verges (Poema 6) que «són silenci i roselles», o la Novençana (Poema 16), «que vol ésser consagrada a la nostra deessa Tanit», una divinitat lunar i la deessa púnica de la fertilitat, de qui ens ocuparem més avant.

\subsection{La Princesa}

Així mateix, el mite de la donzella és en certa manera anàleg al de la Princesa, que apareix al Poema 21, «la que té els llavis de magrana i la virginitat furtiva», del cos de la qual «brolla la passió com un menhir insòlit».

Observem que no es tracta del concepte de princesa a l'ús, amb la imatge arquetípica, tant present en la cultura popular, en la literatura o en els contes de fades, de la dona que necessita ser salvada i rescatada per un heroi. En el poemari, Carmelina Sánchez-Cutillas ens presenta una princesa, una karima-nom femení àrab que significa generosa, noble, pura- despullada de l'abaia (el caftà) i el thaub (la capa), que mostra passió i desig sexual, i que a més té llavis de magrana.

L'elecció de la magrana per a referir-se als llavis femenins és una tria conscient per part de la poetessa, ja que aquesta fruita té un gran simbolisme en totes les cultures presents en el poemari. Així, per posar alguns exemples, els jueus consideren que la magrana és un símbol de la veritat, ja que té 613 llavors, el mateix nombre de manaments de la Torà. A Egipte era considerat un símbol de l'amor i de la fecunditat, i també simbolitza el poder, ja que, oberta, té forma de corona. És un dels símbols de la deessa Hera, esposa de Zeus i la més gran de les deïtats de l'Olimp, que era també 
Verònica Cantó Doménech. Genealogia femenina en Els jeroglífics i la pedra de Rosetta (1976) de Carmelina Sánchez-Cutillas

la deessa del matrimoni, caracteritzada per la fúria i l'ànsia de venjança causades per les constants infidelitats del seu marit. En els versos carmelinians podem apuntar un altre significat de l'ús de la magrana especialment referida als llavis, ja que podem considerar-la una mena de fruita de la passió en el sentit que representa la temptació i el detonant del desig sexual en una imatge poètica de gran sensualitat i erotisme.

\subsection{La reina Ginebra}

En el Poema 8 trobem la referència a la reina Ginebra, en el fragment que diu:

[...] Cercarem urani sota la pell de l'home, quan la ploma blanca del cigne accepte que el Cavaller del llac li escriga un bell poema a Ginebra regina dels alguers (1997: 166).

En aquests versos, Carmelina Sánchez-Cutillas recull el mite artúric referit a la història d'amor entre la reina Ginebra i Lancelot, el cavaller del llac. A més Ginebra és un personatge llegendari en les històries literàries que conformen la matèria de Bretanya, és l'esposa del rei Artur, que comet adulteri amb Lancelot, un dels millors cavallers de la Taula Redona i gran amic del rei, que alhora arrossega el gran pecat del seu amor il legítim, esdevenint la imatge de l'heroi captiu d'una figura femenina. Com sol ocórrer amb molts altres mites, en aquest cas també es castiga la infidelitat femenina, ja que l'adulteri no solament és el detonant de la caiguda de Camelot, i per extensió d'Anglaterra, sinó que converteix la figura de la reina Ginebra en el símbol de la fragilitat humana, de la immoralitat i de la perversitat.

Però Sánchez-Cutillas va més enllà de la llegenda en introduir la figura del cigne blanc, que des de ben antic és la representació de l'espiritualitat, la puresa, l'elegància, la saviesa divina i la purificació, a més de ser l'animal que acompanya deïtats com Afrodita o Apol lo. A més, en la cultura celta, és un animal de poder que es vincula amb el nexe d'unió entre la humanitat i la divinitat, i també simbolitza la fidelitat en les relacions amoroses. Sembla que amb la introducció del cigne, la poetessa redimeix la reina Ginebra del pecat d'adulteri i dona la benedicció a l'amor il lícit entre la reina i el cavaller.

\subsection{La Vestal i l'Abadessa}

D’altres figures sagrades que trobem en el poemari són la Vestal (Poema 19) que és l'encarregada de fer arribar el missatge «cisellat pel foc», «la paraula que denuncia o que lloa» i «la veu del poeta» al jo líric; i l'Abadessa (Poema 20) la intimitat de la qual «serà bandejada pel mesc d'un Temple ignot». Es tracta de dues figures relacionades amb l'exercici del sacerdoci femení pertanyents a èpoques distintes. 
La Vestal era una sacerdotessa romana consagrada a la deessa de la llar, Vesta, amb la missió fonamental de mantenir el foc sagrat, el qual representava la casa, la comunitat i la fidelitat familiar. Les Vestals es consagraven des de xiquetes i havien de viure en castedat i mantenint la virginitat durant els trenta anys que durava el seu sacerdoci. En la societat romana eren una excepció, ja que suposaven l'únic cos femení de la religió i, malgrat estar sotmeses a una gran responsabilitat i témer els càstigs a què s'enfrontaven si incomplien les normes, van ser el col lectiu de dones que van gaudir de més drets i privilegis en l'antiga Roma, que es caracteritzava per un rígid sistema patriarcal.

Per la seua part, l'Abadessa no solament era la cap espiritual d'una comunitat de monges, sinó que també governava administrativament el monestir i, fins i tot, en algunes èpoques va arribar a tenir autoritat legislativa i judicial, a més d'una constatada influència entre els alts estaments de la societat. D’altra banda, és sobradament coneguda i reconeguda l'admiració que Carmelina SánchezCutillas professava a Sor Isabel de Villena, abadessa del Convent de la Trinitat de València, com demostra la carta apòcrifa que l'autora va escriure l'any 1981, encara que datada en 1472, com si fora l'abadessa de la Trinitat, titulada $A$ la reverent e honrada sor Francina de Bellpuig, monja professa al convent de la Puritat e cara cosina nostra, en la qual Sánchez-Cutillas, per mitjà de la veu d'Isabel de Villena, ataca amb una gran ironia la desbocada misogínia de l'Espill de Jaume Roig, com podem comprovar en el fragment que segueix:

\footnotetext{
E és aytal, com lo dit mestre Roig diu al seu llibre que totes les dones som adultres e cantoneres e putanes e alcavotes, e de tota brutea plenes, tant carnalment com espiritual. E de les monges, -sant Miquel Beneït!-, diu que som unes merdoses e ço que no diu lo deixa dir entre ratlla e ratlla, e ben barrejat e lleument amagat en eix estil poètic que ha nom de NOVES RIMADES, e que jo, per riure'm dic CODOLADES (1981: 5).
}

\subsection{La deessa Isis}

Continuem amb la genealogia femenina present en Els jeroglífics $i$ la pedra de Rosetta amb la deessa Isis (Poema 15) que «plora als laberints del Nou Imperi» com el jo líric plora l'absència i la tristesa de l'estimat, a qui evoca de matinada quan «surt de les tenebres de basalt la llum i la vitalitat del teu record», una remembrança que serà perdurable en el dia.

Isis era la deessa de la maternitat i de la fertilitat en l'antic Egipte, germana i esposa d'Osiris (déu de la mort) i mare d'Horus (déu del cel), i a més de ser la Gran Mare, era també venerada com la Gran Maga, ja que va ressuscitar el seu germà i espòs. D'altra banda, Isis va ser l'única deïtat de l'Egipte el culte de la qual es va estendre fins a l'Imperi Romà, i va ser considerada durant l'època grega la deessa dels navegants, amb el que això pot suposar pel que fa al lligam de tots els pobles i cultures de la Mediterrània. A més cal destacar, d'una banda, que, a causa del contacte amb diferents pobles mediterranis, Isis va ser assimilada a la deïtat fenícia d'origen mesopotàmic, Astarté, deessa relacionada amb la fertilitat, la sexualitat i la guerra, i que apareix en el Poema 16. I, de l'altra, que la figura d'Isis asseguda amb el seu fill Horus al braç va ser assimilada pels primers cristians a la figura de la Mare de Déu, representant-la amb una iconografia semblant. 
En el Poema 15 tenim a una de les divinitats egípcies més poderoses, Isis, que no sols coneix els misteris de l'univers, sinó també el nom secret del déu suprem Ra, qui regulava el pas del temps. La dona ací representada per Isis denuncia l'empresonament que pateixen els homes a causa de la por (simbolitzada per «l'amagatall del llop negre»), de la fe, de les creences i dels discursos religiosos imperants que cisallen la voluntat dels éssers humans, representats en aquest cas pels oficis divins de matines i laudes que «són com una dalla d'argent», simbolitzant la mort de la lliure elecció.

\subsection{La deessa Tanit}

En el Poema 16 figura la deessa Tanit a qui «oferim sacrificis sobre l'Ara principal (aqueixa tota plena de diaclases)». Es tracta de la divinitat més important de la mitologia cartaginesa, anàloga a la deessa Astarté, adorada com a divinitat de la Lluna, la sexualitat, la fertilitat i la guerra. Era una deessa verge i entre els seus símbols destacava la magrana, la figa i l'espiga, a més del que es coneix com el signe de Tanit, que és un triangle travessat per dalt per una barra horitzontal i coronat per una circumferència, i que s'ha vist com una representació de la connexió entre el món terrenal amb el celestial. El culte a Tanit es va mantenir fortament arrelat en tot l'àmbit mediterrani, especialment en l'illa d'Eivissa, on va ser venerada fins a l'arribada de la cristianització al segle II, i és precisament en aquesta illa balear on s'han trobat un gran nombre d'estàtues de la deessa.

En aquest cas tenim una deessa amb dos noms (Tanit i Astarté) a qui s'ofereixen sacrificis sanguinaris de donzelles que formen «un tapís de roses vermelles desflorades» sobre un altar de pedra fracturada. La sang i el color vermell esdevenen així la tonalitat que ompli de mort aquest poema. És important assenyalar, com ja va fer M. Àngels Francés (2015: 16), que no sols «la multiplicitat antroponímica reforça la idea de les diverses dimensions i visions d'aquesta divinitat, relacionada amb la naturalesa i la vida, que amb el temps també es va associar amb la guerra», sinó, a més, dona una idea de l'extensió del seu culte que abraça la totalitat de la Mediterrània.

\subsection{La Cariàtide}

En aquest mateix Poema 16 apareix la figura de la Cariàtide, a qui «quan tots els ocells facen un vol, migratori per damunt dels set tossals de Roma, el raïm grec serà el tribut que Creta desitja posar als peus de la Cariàtide». Sembla que la poetessa amb l'oferiment del «raïm grec», vol compensar o reparar el greuge fet pel poble grec a la figura femenina representada per les Cariàtides, quan van esclavitzar les dones de Cària per haver col laborat amb l'invasor persa durant les Guerres mèdiques, després d'assassinar els homes, i van condemnar-les a suportar les càrregues més pesades, entre les quals simbòlicament destaca el pes dels temples d'Atenes, com és el cas de l'Erectèon. 
Verònica Cantó Doménech. Genealogia femenina en Els jeroglífics i la pedra de Rosetta (1976) de Carmelina Sánchez-Cutillas

\subsection{Eurídice}

En el Poema 26 apareix Eurídice que serà l'encarregada de revelar a la poetessa el «gran secret de l'amon» «en aplegar a l'origen del temps i del primer ginebre fossilitzat».

En la mitologia grega, Eurídice és una dríada, és a dir, una nimfa del bosc, però pel que realment és coneguda és per la seua vinculació a un altre mite, el d'Orfeu. Possiblement la història d'amor més antiga que existeix en la mitologia grega és la d'Eurídice i Orfeu, una història amorosa que va anar més enllà, fins i tot, de la mort. Conta la llegenda que Eurídice era una nimfa que es va enamorar d'Orfeu, músic, poeta i fill d'Apol lo, amb qui es va casar. Un dia, fugint d'un intent de rapte, la nimfa va trepitjar un escurçó el verí del qual li va provocar la mort. Orfeu, en descobrir el cos sense vida de l'amada, va anar a buscar la seua ànima al Món dels Morts, on regnaven Hades i Persèfone, a qui va suplicar amb el seu cant que li retornaren l'ànima de la seua estimada. Els déus dels Inferns van accedir a la petició d'Orfeu, amb la condició que no hauria de contemplar el rostre d'Eurídice fins que no hagueren eixit de l'Avern, un condicionant que no es va complir i que va ser la causa que Orfeu perdera la seua estimada per sempre.

És probable que amb la referència al mite d'Eurídice i Orfeu, Sánchez-Cutillas volguera recrear l'amor perdut del jo líric ara que es troba tancada per «tot un reixat fet de silencis» $\mathrm{i}$ en «una mar lentíssima plena de sargassos i de peixos cecs», dues imatges poètiques de gran força que descriuen l'estat d'ànim de la poetessa, on són presents la buidor, el silenci i l'absència.

\subsection{Ariadna}

En el mateix Poema 26 també tenim Ariadna, definida com la dona d'«acerada impaciència» que està custodiada per «un grif fabulós -hermètic i sumptuari», mentre «menta i gingebre aromatitzen» el silenci del jo líric.

Ariadna, princesa de Creta en ser filla del rei Minos i la reina Pasífae, vivia junt al laberint del Minotaure i va ser qui proporcionà a l'heroi Teseu, de qui es va enamorar, el cabdell de fil, que li permetria trobar el camí de retorn i trobar l'eixida del laberint després d'haver matat el monstre, i trencar així el malefici i el compromís d'Atenes d'enviar a Creta cada nou anys un grup de catorze joves, set homes i set dones, que serien sacrificats al Minotaure. Després d'eixir del laberint, Teseu es va emportar la princesa Ariadna, però la va abandonar en l'illa de Naxos, mentre dormia. Després de la fugida de Teseu, hi ha diverses versions sobre què va ocórrer amb Ariadna. Una de les interpretacions és que Artemisa la va matar i una altra versió del mite afirma que es va casar amb el déu Dionís, cosa per la qual Zeus li va concedir la immortalitat.

Però el que ens interessa destacar en aquest article és el poder simbòlic del mite del fil d'Ariadna, i també del laberint, que amb total seguretat Sánchez-Cutillas coneixia bé. Cal partir de la idea que el poder simbòlic del mite ens obri diferents possibilitats d’interpretació i reinterpretació del seu 
Verònica Cantó Doménech. Genealogia femenina en Els jeroglifics i la pedra de Rosetta (1976) de Carmelina Sánchez-Cutillas

significat des d'una perspectiva de gènere, perquè en l'àmbit d'allò que és mític conflueixen elements reals amb continguts ocults, és un enigma que representa un fragment de realitat feta de trossos de veritat. I així, el laberint significaria l'espai d'allò que ens és desconegut, ocult, de l'alteritat que roman en l'interior de cada individu; mentre que el fil esdevé la representació del coneixement que va assolint Ariadna, el nom de la qual significa etimològicament «la de gran puresa», a mesura que desfà el cabdell, que alhora li serveix de guia per a transitar per l'interior del laberint, en el camí vers el coneixement. I així el poder d'Ariadna resideix en el seu fil màgic, que es converteix en l'ancoratge mòbil per a recórrer el seu propi laberint a fi de desxifrar-lo i donar-li sentit, i superar la imatge d’una jove ingènua i enganyada, sotmesa a les circumstàncies externes.

\subsection{L'Emperadriu verge}

I acabem aquest recorregut per la genealogia femenina de Els jeroglifics i la pedra de Rosetta, amb la figura femenina representada per l'Emperadriu verge (Poema 1) davant de la qual, en una imatge poètica altament simbòlica, «el terrisser sagrat trenca el motlle del braseret de mirra». En aquest cas tenim la figura del terrisser, la divinitat androcèntrica que crea l'ésser humà a partir d'una figura de fang i que, a més, ret tribut a l'Emperadriu verge, la qual al nostre parer representa la figura de la Mare de Déu. Així tenim la visió d'una figura femenina poderosa, excelsa, reina de l'Univers, relacionada amb la saviesa, a més de ser creadora de vida i nodridora, que simbolitza i representa la fecunditat universal.

\section{Conclusions}

A tall de conclusió, i al nostre parer, en Els jeroglifics i la pedra de Rosetta, Carmelina Sánchez-Cutillas incorpora tot el seu extraordinari bagatge cultural conformat per un gran coneixement de temes històrics, científics i mitològics, i harmonitza dues de les seus grans passions: la historiografia i la poesia. En aquest poemari, a més de fer una exhibició d'erudició intencionada i conscient, SánchezCutillas fabula un mosaic de peces poètiques de gran originalitat i de difícil comprensió que la situa a l'avantguarda de la literatura catalana del moment com una de les precursores a casa nostra de la poesia simbòlica. Amb aquestes vint-i-huit proses poètiques l'escriptora també pretén oferir, com diu Alpera (1997: 23) «una mena de lliçó intel lectual i estètica per als joves poetes formalistes de com calia fer poesia amb una nova imaginació, amb els recursos formals i, sobretot, erudits que se'n poden extreure sovint del calaix històric de les civilitzacions, de les mitologies, de les diverses cultures universals, pel que tenen de magisteri i força creativa».

Pel que fa a la qüestió objecte d'aquest article, en aquest poemari Carmelina Sánchez-Cutillas denota una profunda consciència de gènere, ens aporta un exemple de genealogia femenina en recuperar-nos tot un seguit de figures femenines mitològiques que conformen la base de la cultura 
occidental i que es presenten davant els nostres ulls caracteritzades per trets com ara la universalitat, la mediterraneïtat, la fortalesa, l'empoderament, la saviesa o la puresa. Totes elles basteixen un univers femení amb veu pròpia que desafien el silenci imperant com les guerreres amazones; que són profètiques i tenen la capacitat de canviar el destí gràcies als sabers assolits a partir de la pròpia experiència com la Sibil la; que no tenen por a mostrar la seua sexualitat com la Princesa o la Reina Ginebra; que no són sols símbols de puresa, sinó també transmissores de la paraula i de l'autoritat com la Vestal o l'Abadessa; que perduren en el temps i en la memòria com Isis o Tanit; que encarnen la fidelitat i la lleialtat com Eurídice; que desentranyen els misteris del laberint com Ariadna; i que són forjadores de vida com l’Emperadriu Verge.

En definitiva, hem intentat demostrar al llarg del present treball que Sánchez-Cutillas ens retorna d'un silenci injust i d'un oblit imperdonable el llegat que conformen el conjunt de dones llegendàries, amb afany de superació, fortes, desafiants, transgressores, rebels, encarregades de la transmissió del coneixement, inspirades per la divinitat, vinculades a les forces naturals i tel lúriques, de gran intel ligència, forjadores del propi destí i creadores de vida que, en paraules de M. Àngels Francés (2015: 27) «lluiten i s'oposen a figures masculines representants de l'autoritat i la llei repressores, que sistemàticament deneguen l'accés als cercles dels iniciats al jo poètic que, com a revenja, les manipula i les subverteix».

A través d'una prosa poètica hermètica, amb l'ús d'un llenguatge figurat, de gran formalisme, i d'un lèxic d'una extraordinària riquesa, les figures femenines s'erigeixen en representants de les veus del passat que retornen al present amb una gran força evocadora, amb afany de denúncia, per a rescatar-nos del silenci, del buit, de la foscor, per a retornar-nos la consciència, la identitat i la dignitat individual i col lectiva de nosaltres les dones, les de ahir, les de hui i les de demà.

En definitiva, la poetessa, mitjançant una arquitectura poètica farcida de simbolismes, ens recorda i ens resitua el valor del llegat femení, empra les figures femenines per a acostar-nos a la frontera entre la part humana i la divina, perquè tot $\mathrm{i}$ que «caminem errants, com la llum d'un estel perdut» $\mathrm{i}$ «encara no sabem desxifrar el vell jeroglífic» (Poema 1), malgrat que «entre el misteri i nosaltres sempre hi ha una pluja roent de profecies incomprensibles» (Poema 7) i «el símbol i el dogma esclavitzen tot un poble de circumcisos» (Poema 9), al capdavall Carmelina Sánchez-Cutillas ens transmet un missatge d'optimisme i d'esperança, ja que podrem eixir vencedors i assolir la libertat i el coneixement perquè «cavalcarem l'espases negres de la mort i del silenci perquè som cavallers de fortuna, i hem fet mal leable l'acer. [...] Així, pot ésser que qualsevol jorn arribem a l'astre d'alumini on creix el llim núbil de la terra» (Poema 2).

Acabem com hem començat, amb la veu de Carmelina Sánchez-Cutillas que ens arriba a través del seu diari personal: «Jo he cercat el desenllaç a tots els vells pergamins, engroguits pel temps i l'angoixa dels homes; jo he cercat la gran resposta, a tots els jeroglífics antics, i la pedra de "Rosetta" emmudia, per no dir-me que l'estranger hi era jo. El crit del guepard i el vol dels ocells i el llarg bramul dels oceans; tot és un plor geogràfic o zoològic, catalogat des de bell antuvi al regne del silenci. Però les meues paraules, eixes que mai no he dit, segueixen sense catalogar, com una fam antiga, immensa, trist» (Diari, 1964). 
Verònica Cantó Doménech. Genealogia femenina en Els jeroglífics i la pedra de Rosetta (1976) de Carmelina Sánchez-Cutillas

\section{Bibliografia}

Alpera, L. (1997) «Introducció», dins Carmelina Sánchez-Cutillas, Obra poètica, València, Consell Valencià de Cultura. Generalitat Valenciana, pp. 9-36.

- (2010) «La lírica de Carmelina Sánchez Cutillas: revisió i abast d’Els jeroglifics i la pedra de Rosetta (1976)», Sobre poetes valencians $i$ altres escrits, vol. 5, Barcelona, Publicacions de l'Abadia de Montserrat, pp. 17-26.

Balaguer, E. (1993) «Els seixanta: el furor d'una dècada. (Balanç de la poesia valenciana)», L'Aiguadolç. Revista de literatura, 18 (primavera 1993), pp. 19-22.

Biedermann, H. (2009) Diccionario de símbolos, Barcelona/Buenos Aires, Editorial Paidós.

Borja Sanz, J. / Francés Díez, M. À. (2020) Carmelina Sánchez-Cutillas. «Des de les fronteres del silenci», València, Acadèmia Valenciana de la Llengua.

Cacciola, A. (2019) "Carmelina Sánchez-Cutillas: deconstrucción y reconstrucción identitaria femenina desde la marginación”, Lectora. Revista de dones i textualitat, 25, pp. 287-306, DOI:10.1344/ Lectora2019.25.18. < https://revistes.ub.edu/index.php/lectora/article/view/29847> [darrera consulta 06/04/2021]

Carbó F. (1991) «Reflexions sobre la poesia de Carmelina Sánchez-Cutillas», Docència. Revista de l'Escola Universitària del professorat d'EGB de Castelló, 6, pp. 193-199.

Carbó, F. / Simbor, V. (1993) La recuperació literària en la postguerra valenciana (1939-1972), València/ Barcelona, Institut Interuniversitari de Filologia Valenciana/Publicacions de l'Abadia de Montserrat.

Del Romero Sánchez-Cutillas, L. (2020) La meva cambra més estimada. La biblioteca de Carmelina SánchezCutillas, València, Vincle editorial.

Falcón, C. / Fernández-Galiano, E. / López Melero, R. (2013) Diccionario de mitología clásica, Madrid, Alianza Editorial.

Francés Díez, M. À. (2015) «Una travessa pel laberint: assaig d’interpretació de Els jeroglifics i la pedra de Rosetta, de Carmelina Sánchez-Cutillas», Caplletra, 58 (primavera 2015), pp.9-28.

Gilbert, S. / Gubar, S. (1979) The Madwoman in the Attic, New Heaven / Londres, Yale University Press.

Lacueva, M. (2020) «Carmelina Sánchez-Cutillas: una dona forta», Conferència pronunciada el 24 de setembre de 2020 en la jornada Feminari. Carmelina Sánchez-Cutillas: dona rebel, València, Acadèmia Valenciana de la Llengua, disponible en https://www.youtube.com/watch?v=dSfy8gGKxgA [darrera consulta 30/03/2021].

Moers, E. (1976) Literary Women, Londres, The Women's Press.

Pérez Montaner, J. (1993) «Carmelina Sánchez-Cutillas: una poètica de la quotidianitat», Revista de Catalunya, 77, pp. 99-110.

SCRIPTA, Revista internacional de literatura i cultura medieval i moderna, núm. 17 / juny 2021 / pp. 485 - 505 
Verònica Cantó Doménech. Genealogia femenina en Els jeroglifics i la pedra de Rosetta (1976) de Carmelina Sánchez-Cutillas

Grimal, P. (2008) Diccionari de mitologia grega i romana, Barcelona, Edicions de 1984.

Sánchez-Cutillas, C. (1962) «La dona a la València medieval. Mite i realitat», Suplement Valencia, diari Levante, 6 de juny.

. (1964) Diari. Inèdit.

- (1981) «A la reverent e honrada sor Francina de Bellpuig, monja professa al convent de la Puritat e cara cosina nostra», Cairell. Revista de literatura, 7, pp. 5-7.

—. (1992) «Dona i literatura», mecanoscrit inèdit dipositat en la caixa 17 del llegat de l'escriptora custodiat en la Biblioteca Valenciana Nicolau Primitiu.

- (1997) Obra poètica, València, Consell Valencià de Cultura. Generalitat Valenciana, pp. 157192.

.(s/d) Semblança autobiogràfica, mecanoscrit inèdit dipositat en la caixa 18 del llegat de l'escriptora custodiat en la Biblioteca Valenciana Nicolau Primitiu.

Showalter, E. (1977) A Literature of Their Own, Princeton, Princeton University.

Ventura Melià, R. (1979) «Carmelina Sánchez Cutillas. Sóc independent, rebel i bohèmia», Valencia Semanal, 29 de juliol - 5 d'agost, pp. 38-39. 